\title{
Postnatal Care Utilization and Associated Factors among Married Women in Benchi-Maji Zone, Southwest Ethiopia: A Community Based Cross-Sectional Study
}

\author{
Tafesse Lamaro Abota $^{1 *}$, NiguseTadeleAtenafu ${ }^{2}$
}

\begin{abstract}
OPEN ACCESS
Citation:Tafesse Lamaro Abota, Niguse Tadele Atenafu.Postnatal Care Utilization and Associated Factors among Married Women in Benchi-Maji Zone, Southwest Ethiopia: Community Based Crosssectional Study. Ethiop J Health Sci.2017;28(3):267.

doi:http://dx.doi.org/10.4314/ejhs.v28i3.4

Received: November 25, 2016

Accepted: December 3, 2016

Published: May 1, 2018

Copyright: (C) 2018 Tafesse Lamaro, et al. This is an open access article distributed under the terms of the Creative Commons Attribution License, which permits unrestricted use, distribution, and reproduction in any medium, provided the original author and source are credited.

Funding: Mizan-Tepi University

Competing Interests:The authors declare that this manuscript was approved by all authors in its formand that no competing interest exists.

Affiliation and Correspondence:

${ }^{1}$ Department of Nursing,Mizan-

TepiUniversity,Mizan,Ethiopia

${ }^{2}$ School of Allied Health, Addis Ababa

University,Addis Ababa,Ethiopia

*Email: lamaro.tafesse@yahoo.com
\end{abstract}

\section{ABSTRACT}

BACKGROUND: In Ethiopia, maternal health service utilization is very low,especially postnatal care $(P N C)$. The percentage of mothers who receive care within two days of childbirth has shown little progress, from $2.4 \%$ in 2000 to $13 \%$ in 2014. However, it is very far below the expected level as compared to other sub-Saharan regions. Therefore, the aim of this study was to assess PNC services utilization and its associated factors among married women in Benchi-Maji Zone, Southwest Ethiopia

METHOD: A cross-sectional studywas conducted from June 15 to August 15, 2015. A total of 801 married women wassampled from randomly selected districts in the zone. Semi-structured questionnaire was used to collect, data and informed consent was obtained from participants. The collected data were entered into the computer using Epi-data version 3.0, and then exported to SPSS Windows version 20.0 for analysis. Logistic regression was used to identify important predictors of PNC utilization.

RESULT: Out of 765 participants, 392(51.24\%) of married women who attended PNC in this study. Out of them, more than two-third $305(77.8 \%)$ attended mainly to immunize their baby. The vast majority, 251(86.3\%), of respondents mentioned lack of information as a main reason for not following PNC, and of them, the majority mentioned that they were appointed to come after 45 days for Family Planning(FP). In comparison with house wives, farmer women were less likely (AOR 0.3, $95 \%$ CI 0.2-0.7) to attend for PNC. Awareness of problems during postnatal period showedthe strongest association in which those who knew the problems were about nine times (AOR 8.7 $95 \%$ CI 5.6-13.4) more likely to attend PNC. Similarly, married women who followedantenatal care $(A N C)$ were more likely (AOR 2.2 $95 \%$ CI 1.1-4.6) to attend PNC in comparison with those who did not attend $A N C$ at all.

CONCLUSION: Residence, ANC follow-up, maternal occupation, awareness about problems of postnatal period had effects on use of $P N C$. In light of this study, providing deep counselling about PNC at the timeof ANC visit and discharge after delivery is strongly recommended. Furthermore, targeting more of rural married women may increase PNC utilization.

KEYWORDS: PNC, Benchi-Maji, Southwest Ethiopia, Crosssectional study, Mizan-Tepi University 


\section{INTRODUCTION}

Globally, Maternal Mortality (MM) remains a major challenge of health systems. An estimated 287,000 maternal deaths occurred in 2010 and showed a decline of $47 \%$ from levels in 1990. In 2010 , 56\% of world MM occurred in the subSaharan Africa. The global Maternal Mortality Rate (MMR) in 2010 was 210 maternal deaths per 100000 live births, down from 400 maternal deaths per 100,000 live births in 1990. The MMR in developing regions was 15 times higher than the one in developed regions(1).Sub-Saharan Africa had the highest MMR at 500 maternal deaths per 100000 live births (2). Ethiopia is one of the countries in sub-Saharan Africa with markedly high MMR. The maternal mortality ratio (MMR) in Ethiopia has stagnated at 676 per 100,000 live births after declining from 871 per 100,000 live births in 2000 to 673 in 2005 . Efforts to reduce maternal mortality have been made and again should focus on reducing the probability of having high risk pregnancies, serious complications of pregnancy or childbirth and improving the outcomes for women with complications (3).

Millions of women who survive childbirth suffer from pregnancy related injuries, infections, diseases and disabilities, often with lifelong consequences. In fact, most of these deaths and conditions are preventable. On the other hand, the scientific evidence indicates that approximately $80 \%$ of maternal deaths could be averted if women had access to essential maternity and basic healthcare services (4).Maternal healthcare service utilization is important for the improvement of both maternal and child health (5). Boomingmaternal and child health rely on increasing the percentage of women following ANC, giving birth in health institutions with the assistance of trained staff and having PNC services, which is the central goal of the safe motherhood and child survival movements (6). From these maternal health services, the postnatal period is a critical phase in the lives of mothers and newborn babies. Most maternal and infant deaths occur in the first month after birth, and almost half of postnatal maternal deaths occur within the first 24 hours (7). However,the brief focuses on postnatal care and the importance of antenatal and intrapartum care within a continuum are recognized to have the greatest impact on maternal and newborn survival. Despite this, an analysis of Demographic and Health Survey (DHS) data from 23 sub-Saharan African countries found that only $13 \%$ of women who delivered at home received postnatal care within 2 days of birth (8).

In Ethiopia, maternal health service utilization is very low in general and postnatal care in particular. The percentage of mothers who receives PNC within two days of childbirth has shown little progress from $2.4 \%$ in 2000 to $13 \%$ in 2014. However, it is very far below the expected level as compared to the cases in other subSaharan regions. In addition, only less than $1 \%$ of the women who delivered at home received postpartum care within 42 days, as of the most recent DHS. This has declined to $3.5 \%$ as reported in the 2000 DHS. For this low postnatal care service utilization, socioeconomic and demographic factors are associated with relevant uptake of postpartum care (9-11). As compared to others region in the country (Ethiopia), the utilization rate of postnatal care in the south region was recorded as the second lowest (6.4\%) next to Somali (4.5\%) according to 2011 Demographic and Health survey (12). Despite the fact that postnatal care is critical for better improvement of maternal and child health and it is a period of major maternal death occurrences, little is known about the use and factors influencing the use of these services in peripheral area in the region in general and particularly in Benchi-Maji Zone. Therefore, the aim of this study was to assess postnatal care utilization and its associated factors among married women in Benchi-Maji Zone, Southwest Ethiopia.

\section{METHODS AND MATERIALS}

Study setting and period:The study was conducted in Bench-Maji Zone in the Southern Regional State. It is situated at about $561 \mathrm{~km}$ far from Addis Ababa, the capital city of Ethiopia, in

DOI: http://dx.doi.org/10.4314/ejhs.v28i3.4 
the southwest direction with a total population of $760,313($ Male $=380841$, Female $=379,472)$. The majority $(86 \%)$ of the population lives in rural areas (13). There are a total of 218 health facilities in the zoneand further quantified as one General hospital, 35 Health Centers and 182 Health post. It is also a center of one university and one health science college (Zonal Health Department Report).The study was conducted from June 15 /2015 to August $15 / 2015$.

Study design: The study was a community based cross-sectional in design and was conducted to assess postnatal care service utilization and its associated factors among married women in Benchi-Maji Zone, Southwest Ethiopia.

Source population: The source populations of this study were all childbearingmarried women residing in the zone.

Study population: All childbearingmarried women who had given at least one birth in the past two years preceding the survey from randomly sampled districts, were considered as the study populations

Sample size determination:A sample size of 801 was determined from three randomly selected districts in the zone by using a formula for estimation of single population proportion with the assumption of $95 \%$ confidence level, the margin of error of $5 \%$ and taking aproportion of PNC $\mathrm{P}=61.6 \%$ to obtain maximum sample size $(15)$ with design effect of 2 . In addition, the nonresponse rate of $10 \%$ of the determined sample was added upon the calculated sample size, and then the total sample size of 801 was taken.

Sampling procedure: Probability sampling methods were used for selecting the required samples from the study areas. Administratively, there are ten districts in the Benchi-Maji Zone with one administration town (Mizan-Aman Town). From 11 districts, three districts; namely, Mizan-Aman Town, Shey-Bench and MenitShasha was randomly selected. The selections of two Kebles (lowest administrative units) were carried out by using the lottery method from three districts.Then, recording the number of households in six selected Kebles was done. After that, the calculated sample size was obtained by using probability proportional to the size of household in the six randomly selected Kebles. From the six randomly sampled kebles, a total of 801 samples was selected systematically. Lottery method was used for households with more than one eligible woman. In case there were households with no eligible women, the immediate next households were interviewed. Revisits of two times were made in case eligible respondents were not available at the time of the survey. Regarding women who had more than one child, the most recent birth was taken.

Study variables: The dependent variable in this study isutilization of postnatal care. On the other hand, the independent variables aresociodemographic factors (age of mother, religion, ethnicity, occupation, education, household economy), obstetric history, parity, gravidity, birth interval, mothers child experience).

Data collection techniques and procedures: Pretesting was conducted among similar populations outside of the study area. Therefore, pre-tested, semi-structured,aninterviewer-administered questionnaire was employed to collect the data. The questionnaire was adopted and modified from EDHSand the different relevant literature. The English version of the questionnaire was translated into Amharic language for better understanding by the data collectors. The questionnaire,thentranslated back into English to check for its consistency. Six Diploma Midwives who fluently speakthe local language were trained as interviewers, and three BSc nurses were recruited for supervision of data collection. The translations of the questionnaire were checked by two people who are fluent in both languages. A two days training was given for data collectors and supervisors. The training was focused on explanation of the study purpose, interviewing technique, data handling techniques, and ethical considerations during data collection. Data collection guidelines were given to data collectors. The supervisorsmonitored data collection process face-to-face and through phone communication.

Data quality control:Pretest of the questionnaire was carried out to maintain data quality. Based on the finding of the pretest, data collectors were reoriented, and the questionnaire was modified as necessary. Data were collected by the trained

DOI: http://dx.doi.org/10.4314/ejhs.v28i3.4 
six Diploma Midwives from the selected kebles. On the days of data collection, the principal investigator and the supervisor monitored the data collection process by checking completeness of the data.The data were checked again for its completeness before data entry, and the cleaning process was done by running a simple frequency after data entry for its consistency.

Data processing and analysis:After checking for its completeness, the data was entered into a computer using Epi-data version 3.0. The data were cleaned accordingly and exported to SPSS Windows version 20.0 for analysis. Frequency, percentage, chi-square were used to describe the study population in relation to relevant variables. Two step logistic regressions [bivariate and multivariate] were used to see the effect of the independent variables on the dependent variable by controlling confounders. Statistical significance was set at $95 \%$ level of significance. Tables and bar graphs were used to present the data.

Ethical consideration:Ethical clearance was obtained from Mizan-Tepi University Ethical Review Committee.Permissionwas secured from all Selected Kebles of Bench-Maji Zone. All the study participants were informed about the purpose of the study, their right to refuse and informed verbal consent was obtained prior to the interview. The women were told that the information obtained from them would be kept confidential.

\section{RESULTS}

Socio-demographic characteristics of married women in Benchi-Maji Zane 2015:A total of 801 women who had given birth in the last two years preceding the survey were interviewed. From all eligible women in the selected sample, 765 responded to the questionnaire which made the response rate to be $95.51 \%$, and the data was used for all subsequent analysis. The rest, 36(4.49\%), women's responses were discarded for the incompleteness of main variables and inconsistencies among completed variables. The mean age of the mothers was 25.43. The mean monthly income of study participants was 1146.19
Ethiopian Birr. The average family size of study participants was 4 with a minimum of 2 and maximum of 11.Bench and Amhara were the predominant ethnic groups accounting for 188 $(24.6 \%)$ and $155(20.3 \%)$ respectively. The majority of the mothers were followers of Protestantism, 369(48.2\%), followed by Orthodox Christianity, 281(36.7\%). Out of all the study participants, 306(40\%) were not able to read and write while the majority of their husbands, $308(42.5 \%)$, attended primary school. About $73.2 \%$ of the mothers were housewives while $36.3 \%$ of their husbands were farmers followed by merchants $(34.3 \%)$ (Table 1$)$.

The obstetric history of married women on postnatal care services utilization in BenchMaji Zone, Southwest Ethiopia,2015:Out of all the respondents included in the study, $49.2 \%$ gave birth to their first child in the age range of 20-24 with the mean age during first child birth of $20.2(\mathrm{SD}=2.75)$. Teenage pregnancy $(15-19)$ which is a major health concern because of its association with higher morbidity and mortality for both the mother and the child was also significantly higher among the study participants (43.7\%).Among 765 women who delivered in the last two years, $28(3.7 \%)$ had children less than a year apart. Concerning the outcomes of pregnancy, $10(1.31 \%)$ of the mothers never gave live births, whereas $37(4.9 \%)$ and $31(4 \%)$ of them had a history of stillbirth and abortion respectively.The majority, 513(67.1\%), of respondents jointly decided the number of children they have.

Awareness and practice on postnatal care service utilization among married women in Benchi-Maji zone, southwest Ethiopia, 2015: The respondents were asked whether they had ever heard about postnatal care services or not. The vast majority, 683(89.3\%), of them replied that they ever heard about PNC services mainly from a health institution by health professionals, 492(72.04\%), though some of them did not know the benefits of PNC 39(5.71\%). The married women were also asked whether they knew the benefits of using postnatal care or not. The most frequently mentioned benefits of PNC 
were to give opportunity for family planning and $278(43.2 \%)$ of the respondents respectively. to check conditions of infants by $429(66.6 \%)$ and

Table 1: Socio-demographic characteristics of married women in Bench-Maji Zone, 2015

\begin{tabular}{|c|c|c|c|c|c|}
\hline Variable & Number & percent & Variable & Number & percent \\
\hline \multicolumn{3}{|l|}{ Maternal age $n=765$} & \multicolumn{3}{|l|}{ Maternal occupation $n=765$} \\
\hline $15-19$ & 21 & 2.7 & House wife & 560 & 73.2 \\
\hline $20-24$ & 319 & 41.7 & Merchant & 75 & 9.8 \\
\hline $25-29$ & 271 & 35.4 & Farmer & 60 & 7.8 \\
\hline $30-34$ & 109 & 14.2 & Government Employee & 44 & 5.8 \\
\hline$>35$ & 45 & 5.9 & Other*** & 26 & 3.4 \\
\hline \multicolumn{3}{|l|}{ Ethnicity $n=765$} & \multicolumn{3}{|l|}{ Husband Occupation n=724 } \\
\hline Bench & 188 & 24.6 & Farmer & 263 & 36.3 \\
\hline Amhara & 155 & 20.3 & Merchant & 248 & 34.3 \\
\hline Menit & 148 & 19.3 & Government Employee & 99 & 13.7 \\
\hline Kaffa & 140 & 18.3 & Daily laborer & 85 & 11.7 \\
\hline Silte & 41 & 5.4 & Farmer & 29 & 4.0 \\
\hline Oromo & 33 & 4.3 & & & \\
\hline Other* & 60 & 7.8 & & & \\
\hline \multicolumn{3}{|l|}{ Religion $n=765$} & \multicolumn{3}{|l|}{ Availability of TV $/$ Radio $=765$} \\
\hline Protestant & 369 & 48.2 & Yes & 483 & 63.1 \\
\hline Orthodox & 281 & 36.7 & No & 282 & 36.9 \\
\hline Islam & 96 & 12.5 & & & \\
\hline Other** & 19 & 2.5 & & & \\
\hline \multicolumn{3}{|c|}{ Maternal Educational level $n=765$} & \multicolumn{3}{|l|}{ Husbands Educational level $n=724$} \\
\hline Cannot read and write & 306 & 40.0 & Primary school $(1-8)$ & 308 & 42.5 \\
\hline Able to read and write & 22 & 2.9 & Cannot read and write & 165 & 22.8 \\
\hline Primary school (1- 8) & 312 & 40.8 & Secondary school (10-12) & 111 & 15.3 \\
\hline Secondary school 10-12) & 80 & 10.5 & Diploma and above & 89 & 12.3 \\
\hline College diploma and above & 45 & 5.9 & Able to read and write & 51 & 7.0 \\
\hline
\end{tabular}

Note* Hadiya, Wolayita, Gamo, Tigre,Sheko,Sheka,Yem,Dawero,Dize,Gurage **Traditional religion, Catholic and Apostolic ***Private business, Driver, Carpenter, Student, Religious leader, daily laborer

Out of all the respondents included in the study, $523(76.57 \%)$ replied that they knew danger signs of postnatal period. The postpartum hemorrhage (bleeding) was the frequently mentioned danger sign among 489(93.5\%) of the respondents.From half, 392(51.24\%), of the married women who attended PNC in this study, more than two-third, $305(77.8 \%)$, attended mainly to immunize their baby.The majority, 251(86.3\%), of the respondents mentioned lack of information as a main reason for not following postnatal care, while out of them, the majority mentioned that they were appointed to come after 45 days for family planning. On the other hand, 32(11\%) of the respondents did not follow PNC due to mistreatment by health professionals, waiting more time at the facility, husbands' disapproval and forgotten appointments. The future intention of postnatal care service utilization was also sought.Out of all the study participants, 672(98.4\%) married women intended to use PNC in the future. Only $11(1.6 \%)$ of the respondents replied that they would not come even if they give birth again because of mistreatment by health professionals, husband disapproval and economic problems (Table 2).

DOI: http://dx.doi.org/10.4314/ejhs.v28i3.4 
Table 2. Awareness and practice of postnatal care service utilization among married women in Bench - Maji Zone, 2015

\begin{tabular}{|c|c|c|}
\hline Variables & Number & Percent \\
\hline \multicolumn{3}{|l|}{ Ever heard about PNC $n=765$} \\
\hline Yes & 683 & 89.3 \\
\hline No & 82 & 10.7 \\
\hline \multicolumn{3}{|l|}{ The sources of information about $P N C$ services $n=683$} \\
\hline Health institution/ care provider & 492 & 72.04 \\
\hline Radio/TV & 108 & 15.81 \\
\hline Family/Relatives & 67 & 9.81 \\
\hline Other* & 16 & 2.34 \\
\hline \multicolumn{3}{|l|}{ Know that $P N C$ service has an advantage $n=683$} \\
\hline Yes & 644 & 94.23 \\
\hline No & 39 & 5.71 \\
\hline \multicolumn{3}{|l|}{ Listed benefits of PNC $n=644$} \\
\hline To give opportunity for family planning & 429 & 66.6 \\
\hline To check conditions of infants & 278 & 43.2 \\
\hline To get information how to feed their infant & 236 & 36.6 \\
\hline To detect and treat health problems during the postpartum period & 202 & 31.4 \\
\hline Vaccination & 174 & 27.02 \\
\hline Other** & 4 & 0.8 \\
\hline \multicolumn{3}{|l|}{ Do they know problems that may arise during $P N$ period $n=683$} \\
\hline Yes & 523 & 76.57 \\
\hline No & 160 & 23.43 \\
\hline \multicolumn{3}{|l|}{ Listed problems that may arise during $P N$ period $n=523$} \\
\hline Bleeding $(\mathrm{PPH})$ & 489 & 93.5 \\
\hline Maternal death & 191 & 36.5 \\
\hline Sepsis & 79 & 15.1 \\
\hline Other*** & 32 & 6.12 \\
\hline \multicolumn{3}{|l|}{ Attended PNC in the six weeks after delivery $n=765$} \\
\hline Yes & 392 & 51.24 \\
\hline No & 373 & 48.46 \\
\hline \multicolumn{3}{|l|}{ Reason why they visit clinic for $P N C$ n $=392$} \\
\hline For immunization of baby & 305 & 77.8 \\
\hline To start family planning & 254 & 64.8 \\
\hline Because they told to come & 167 & 42.6 \\
\hline Other**** & 24 & 6.12 \\
\hline \multicolumn{3}{|l|}{ Type of service they get during their $P N$ visit $n=392$} \\
\hline Immunisation of baby & 333 & 84.9 \\
\hline Family planning services & 281 & 71.7 \\
\hline Counselling & 97 & 24.7 \\
\hline Breast feeding education & 92 & 23.5 \\
\hline Physical examination & 75 & 19.1 \\
\hline \multicolumn{3}{|l|}{ Number of PN visits within 6 weeks after delivery $n=392$} \\
\hline Less than recommended 3 or more visit & 325 & 82.9 \\
\hline Within recommended 3 or more visit & 67 & 17.1 \\
\hline \multicolumn{3}{|l|}{ Time for the first $P N$ visit $n=392$} \\
\hline Immediately after delivery & 101 & 25.8 \\
\hline Within 24 Hrs & 208 & 53.1 \\
\hline$>2$ days & 82 & 20.9 \\
\hline
\end{tabular}

*From school (education) and more than one source

**Better quality of life, prevent child death, circumcision

*** Peurperalpsychosis, anemia, child disease and death,cramp, Retained placenta

****Bleedindpost delivery, to check CS scar,Circumssision, to make sure they can back to work, because of illness.

DOI: http://dx.doi.org/10.4314/ejhs.v28i3.4 
Factors associated with postnatal care services utilization among married women in BenchiMaji Zone, Southwest Ethiopia, 2015:A number of factors may influence respondents' postnatal care utilization. To identify the factors associated with postnatal care service utilization, logistic regression was used. Bivariate analysis of the selected factors for this study (maternal age, religion, maternal educational level, maternal occupation,marital status, availability of TV/radio, residence, knowledge of problems that may occur some days after delivery, place of delivery for their last child, ANC follow-up and maternal age during first pregnancy) was performed. Some factors like maternal marital status and maternal age have not shown a statistically significant association with postnatal services utilization in bivariate logistic regression.

After adjusting for confounding factors with multivariate analysis, religion, maternal occupation, residence, maternal age during the first pregnancy, knowledge of problems during post-natal period and ANC follow-up maintained statistically significant associations with postnatal service utilization. Among the factors which were associated with PNC utilization, residence and awareness about problems that may occur during postnatal period had the strongest associations with PNC service utilization.

The probability of seeking PNC was six-folds (AOR 6.1,95 \% CI 1.7-21.5) higher among married women who were following Traditional Religion, Catholic and Hawariyat in comparison with those who follow Protestantism. In comparison with housewives, those mothers who were farmers were less likely (AOR 0.3, $95 \% \mathrm{CI}$ $0.2-0.7)$ to attend PNC. Similarly, mothers who were from semi-urban (AOR 0.3,95\% CI 0.2-0.5) and rural areas (AOR 0.2,95\% CI 0.1, 0.4) were less likely to attend postnatal care in comparison with those from urban areas.

Maternal age during first pregnancy also showed significant association in which mothers in the age range of 20-24 during their first pregnancy were greater than one and a half times (AOR $1.795 \%$ CI 1.2-2.5) more likely to attend PNC in comparison with mothers in the age group of 15-19 during their first pregnancy. Knowledge of problems during postnatal period was among the factors which showed the strongest association in which those who know the problems were about nine times (AOR $8.795 \%$ CI 5.6-13.4) more likely to attend PNC. Similarly, ANC follow-up even if it was below the recommended four visits was more likely (AOR $2.295 \%$ CI 1.1-4.6) to attend for PNC in comparison with the case of women who did attend ANC at all (Table 3).

\section{DISCUSSION}

The study was aimed at addressing the barricades to postnatal care utilization in Bench-Maji Zone in the Southern part of Ethiopia. The finding reveals that the majority of mothers $(89.3 \%)$ ever heard about PNC. For $72.04 \%$ of mothers, health professionals were the main source of information for PNC. This was slightly higher than study conducted in Gondar Zuria (15). The possible reason may be differences in the studied populations. About two-third (77.8\%) of the mothers attended PNC to vaccinate their baby, and this finding is similar to other studies $(15,16)$.

The study has documented that $51.24 \%$ of the married women attended postnatal care within six weeks after their last child delivery. The finding of this study was consistent with a cross sectional study conducted in Adwa Town which found that 264(78.3\%) mothers had attended postnatal care service (16). However, this finding is higher than a population-based study conducted elsewhere in the country $(17,18)$. This might be because, in this study, every visit was counted as a postnatal care. On the contrary, the finding of this study was lower than a cross-sectional study conducted in Gondar Zuria District which found that from 820 mothers, $66.83 \%$ obtained PNC (15). Although it was higher than some studies, yet it has not reached the recommended level ( $\mathrm{PNC}=90 \%)$ by WHO. This might be attributed to increased home delivery and lack of focus on mothers for coming back again when discharging mothers.

In this study, lack of information was mentioned as a main reason for not following PNC by the majority of the married women $(86.3 \%)$, and from them, the majority mentioned that they were appointed to come after 45 days for FP. This finding is also in agreement with studies conducted elsewhere in the country (16, 18 , 19). Unlikely, the finding from elsewhere reveals that having no health problem to attend, illness, and cost to obtain the services were the major reasons for not attending postnatal care were (21). In this regard, simply having awareness about PNC services did not

DOI: http://dx.doi.org/10.4314/ejhs.v28i3.4 
Table 3: Factors associated with PNC service utilization among married women of in Bench -Maji Zone, 2015

\begin{tabular}{|c|c|c|c|c|c|c|c|c|}
\hline \multirow[t]{3}{*}{ Variables } & \multicolumn{4}{|l|}{$\mathrm{PNC}$} & \multirow{3}{*}{$\begin{array}{l}\text { COR } \\
(95 \% \mathrm{CI})\end{array}$} & \multirow[t]{3}{*}{ P-value } & \multirow{3}{*}{$\begin{array}{l}\text { AOR } \\
(95 \% \mathrm{CI})\end{array}$} & \multirow[t]{3}{*}{ P-value } \\
\hline & \multicolumn{2}{|c|}{ No } & \multicolumn{2}{|c|}{ Yes } & & & & \\
\hline & No & $(\%)$ & No & $(\%)$ & & & & \\
\hline \multicolumn{9}{|l|}{ Maternal Age } \\
\hline $15-24$ & 165 & 44.2 & 175 & 44.6 & 1 & & & \\
\hline $25-34$ & 183 & 49.1 & 197 & 50.3 & $1.02(.8,1.4)$ & .921 & & \\
\hline $35-44$ & 25 & 6.7 & 20 & 5.1 & $.8(.4,1.4)$ & .377 & & \\
\hline \multicolumn{9}{|l|}{ Religion } \\
\hline Protestant & 204 & 54.7 & 165 & 42.1 & 1 & & 1 & \\
\hline Orthodox & 128 & 34.3 & 153 & 39.0 & $1.5(1.1,2.02)$ & $.014 *$ & $.8((.5,1.2)$ & .196 \\
\hline Islam & 35 & 9.4 & 61 & 15.6 & $2.2(1.4,3.4)$ & $.001 *$ & $1.1(.6,2.0)$ & .837 \\
\hline Other** & 6 & 1.6 & 13 & 3.3 & $2.7(1.0,7.2)$ & $.051^{*}$ & $6.1(1.7,21.5)$ & $.005^{*}$ \\
\hline \multicolumn{9}{|c|}{ Maternal Educational level } \\
\hline Can’t read & 163 & 43.7 & 143 & 36.5 & 1 & & 1 & \\
\hline$<=$ Primary & 159 & 42.6 & 175 & 44.6 & $1.3(.9,1.7)$ & .153 & $.8(.5,1.3)$ & .365 \\
\hline$>=$ Secondary & 51 & 13.7 & 74 & 18.9 & $1.7(1.1,2.5)$ & $.019 *$ & $.7(.4,1.3)$ & .233 \\
\hline \multicolumn{9}{|c|}{ Maternal occupation } \\
\hline House wife & 261 & 70.0 & 299 & 76.3 & 1 & & 1 & \\
\hline Gov’t & 17 & 4.6 & 27 & 6.9 & $1.4(.7,2.6)$ & 309 & $1.5(.7,3.3)$ & .356 \\
\hline Merchant & 34 & 9.1 & 41 & 10.5 & $1.1(.7,1.7)$ & .835 & $.8(.5,1.5)$ & .553 \\
\hline Farmer & 47 & 12.6 & 13 & 3.3 & $2(.1, .5)$ & $.000 *$ & $.3(.2, .7)$ & $.005^{*}$ \\
\hline Other** & 14 & 3.8 & 12 & 3.1 & $.8(.3,1.7)$ & .471 & $.4(.1,1.0)$ & .047 \\
\hline \multicolumn{9}{|c|}{ Maternal Marital Status } \\
\hline Married & 350 & 93.8 & 374 & 95.4 & 1 & & & \\
\hline Other & 23 & 6.2 & 18 & 4.6 & $.7(.4,1.4)$ & .335 & & \\
\hline \multicolumn{9}{|c|}{ Availability of TV/Radio } \\
\hline No & 162 & 43.4 & 120 & 30.6 & 1 & & 1 & \\
\hline Yes & 211 & 56.6 & 272 & 69.4 & $1.7(1.3,2.3)$ & $.000^{*}$ & $1.0(.6,1.6)$ & .989 \\
\hline \multicolumn{9}{|l|}{ Residence } \\
\hline Urban & 142 & 38.1 & 257 & 65.6 & 1 & & 1 & \\
\hline Semi urban & 98 & 26.3 & 68 & 17.3 & $.4(.3, .6)$ & $.000^{*}$ & $.3(0.2,0.5)$ & $.000 *$ \\
\hline Rural & 133 & 35.7 & 67 & 17.1 & $.3(.2, .4)$ & $.000 *$ & $.2(0.1,0.4)$ & $.000^{*}$ \\
\hline \multicolumn{9}{|c|}{ Maternal age during first pregnancy } \\
\hline $15-19$ & 185 & 49.6 & 149 & 38.0 & 1 & & 1 & \\
\hline $20-24$ & 162 & 43.4 & 214 & 54.6 & $1.6(1.2,2.2)$ & $.001 *$ & $1.7(1.2,2.5)$ & $.005^{*}$ \\
\hline $25-34$ & 26 & 7.0 & 29 & 7.4 & $1.4(.8,2.5)$ & .264 & $2.0(.9,4.2)$ & .082 \\
\hline \multicolumn{9}{|c|}{ Knowledge of problems during post natal period } \\
\hline No & 191 & 48.8 & 51 & 87.0 & 1 & & 1 & \\
\hline Yes & 182 & 51.2 & 341 & 13.0 & $7.0(4.9,10.0)$ & $.000 *$ & $8.7(5.6,13.4)$ & $.000 *$ \\
\hline \multicolumn{9}{|l|}{ ANC follow up } \\
\hline None & 64 & 17.2 & 18 & 4.6 & 1 & & 1 & \\
\hline$<4$ & 123 & 33.0 & 112 & 28.6 & $3.2(1.8,5.8)$ & $.000^{*}$ & $2.2(1.1,4.6)$ & $.036^{*}$ \\
\hline$>=4$ & 186 & 49.9 & 262 & 66.8 & $5.0(2.9,8.7)$ & $.000^{*}$ & $2.0(.9,4.1)$ & .078 \\
\hline \multicolumn{9}{|c|}{ Place of delivering last child } \\
\hline Home & 119 & 31.9 & 47 & 12.0 & 1 & & 1 & \\
\hline H.Facility & 254 & 68.1 & 345 & 88.0 & $.3(.2, .4)$ & $.000 *$ & $1.0(.6,1.8)$ & .997 \\
\hline
\end{tabular}

* Significant association, **Traditional religion, Catholic, Hawariyat, *** Private business, Driver, Carpenter, Student, Religious leader, daily laborer

DOI: http://dx.doi.org/10.4314/ejhs.v28i3.4 
substantiate their use if do not practice it. It is a critical time to give many cares which play a vital role for both maternal and child health. It also needs intensive counselling during discharge of clients and home visits.

In this study, residence, religion, maternal occupation, maternal age during the first pregnancy, knowledge of problems during postnatal period and ANC follow-up maintained statistically significant associations with PNC.

Mothers within the age range of 20-24 at first child birth were more likely to attend PNC in comparison with mothers within the age range of 15-19 at their first childbirth. This may be attributed to the fact that the more advance in age, the more mature in health care seeking. On contrary to this, the findings from other national studies revealed that there was no effect of maternal age on PNC utilization (9). This may be explained bythe difference in sample population size and study period.

In this study, place of residence had an effect on postnatal care utilization. Mothers who were from rural dwellings were less likely to follow postnatal care compared with mothers who were from urban settings. This similar with the study from GonderZuria districts that showed that urban mothers were more likely to receive $\mathrm{PNC}$ than rural mothers (15), and it also coincides with national findings of 2011(9).The possible reason might be that urban women had more access to information, education and communication (IEC), or it is easier for urban women to reach postnatal services than it is for rural mothers.

Mothers who had antenatal follow-up were more likely to follow PNC than mothers who did not have antenatal follow-up. This has also been revealed in other similar studies $(15,21)$. This could be due to the effect of ANC to consecutive maternal health care service linkage. This finding is different from the study conducted in Adwa which found no association between antenatal visit and postnatal service utilization (16).

This study found that occupation of women was independently associated with having received postnatal care. Similarly, studyin Adwa showed that self-employed mothers were 9.1 times more likely to have had PNC than women who did not have any job (16). Other studies also reported similar findings (20). On the other hand, work status of women was not found to be associated with the use of PNC services $(9,15)$. The finding of this study was similar to a study conducted elsewhere in the Sidama Zone (17). However, the 2011 national finding of the country revealed that listening tothe radio and watching television programs had no effect on use of PNC services (9). This study reveals that mothers who were aware of the problems of postnatal period were more likely to use PNC compared with mothers were not aware. This is different reports from other studies (16, 21, 22).

Unlike the findings of this study, literacy status was significantly associated with PNC service utilization in which illiterate women were $24.7 \%$ less likely to use PNC services compared with literate women (17). Other similar studies identified that literacy levels of mothers wereassociated with use of PNC services(20). On the other hand, mothers' level of education did not determine PNC as reports from other studiesindicated $(15,16)$.

In conclusion, awareness and utilization of postnatal care among married women in the study area is more or less good comparatively with findings of other studies in the region. However, it is far below the World Health Organization recommended level (it should be at least 90\%) for sub area. It is also the remotest from Health sector Development plan (100\%) of the country for postnatal care. Religion, maternal occupation, residence, maternal age during first pregnancy, knowledge of problems during postnatal period and ANC follow-up maintained statistically significant associations with PNC. Therefore, in light of this study, all motherhood services stakeholders (bothgovernmental and non-governmental organizations) are should give due attention to women empowerment, early marriage, deep counselling about the postnatal care at a time of ANC visit and discharge after delivery to increase postnatal care up-take. Furthermore, creating awareness on utilization of postnatal care through community leaders and by targeting more rural married women is also strongly recommended.

The limitation of this study might be subject to recall bias since it was based on past events. In addition,methodological perspectives, it lacks triangulations. Since the study is cross-sectional in nature, it may not show temporal relation.

\section{ACKNOWLEDGEMENTS}

First and foremost, our heart-felt gratefulness goes to Mizan-Tepi University, Institute of Research and Community Service, for arranging the opportunity to carry out this study. We wish to express deep appreciation to health departments of Benchi-Maji Zone, Sheko, Semen Bench, Debub Bench and MizanAman Town for their cooperation when we were conducting this study.Last but not least, our appreciation extends to all the study participants who provided the research data. 


\section{REFERENCES}

1. United Nations Economic Commission for Africa, African Union, African Development Bank Group and UNDP. Assessing Progress in Africa towards the Millennium Development Goals; Food security in Africa: Issues, challenges and lessons. MDG report2013.Available

at:http://www.afdb.org/.../afdb/.../Millennium Dev elopment Goals MDGs Report 2013.p...access ed on March 15,2015

2. World Health Organization,UNICEF, UNFPA,WORLD BANK.Trends in Maternal mortality $1990-2010$. ; 2012.

3. United Nation Population Fund Report. Trends in Maternal health in Ethiopia (Challenges in achieving the MDG for maternal mortality); Indepth Analysis of the EDHS 2000-2011. December, 2012

4. World Health Organization. Progress in Global Measles Control and Mortality Reduction,2000 2006. Morbidity and Mortality Weekly Report. 2007; 82(48):422.

5. Stephenson R,Baschieri A,Clementset S,et.al. Contextual Influences on the Use of Health Facilities for Child Birth in Africa. American Journal of Public Health. 2006; 96(1):84-93.

6. Kesterton AJ, Cleland J, Sloggett A, Ronsmans C. Institutional Delivery in Rural India: The Relative Importance of Accessibility and Economic Status. BMC Pregnancy \& Child Birth. 2010; 10(30) 1-9.

7. WHO. Every Newborn, An Executive Summary for The Lancet's Series. May 20, 2014.Available at:

URL:http://www.who.int/entity/pmnch/media/new s/2014/lancet exec summ.pdf?ua. Acessed on March 15, $20 \overline{15}$

8. World Health organization, Postnatal care Guidelines,March 2015

9. Tarekegn S, Lieberman L, Giedraitis V. Determinants of maternal health service utilization in Ethiopia: Analysis of the 2011 Ethiopian Demographic and Health Survey. BMC Pregnancy and Childbirth 2014; 14:161

10. Central Statistical Agency (Ethiopia) and ORC Macro: Ethiopia Demographic and Health Survey 2000. Addis Ababa, Ethiopia and Calverton, Maryland, USA: Central statistical Agency and ICF International; 2001.

11. Ethiopia Mini Demographic and Health Survey 2014. Addis Ababa: Central Statistical Agency; 2014.
12. Kassu M, Eshetu W. Factors affecting maternal health care services utilization in rural Ethiopia: A study based on the 2011 EDHS data. Ethiop. J. Health Dev. 2013; 27(1):16-24.

13. Central Statistics Agency (Ethiopia).Summary and Statistical Report of the 2007 Population and Housing Census. Addis Ababa.Federal Democratic Republic of Ethiopia Population and Census Commission; 2008.

14. Amantie M,Abera M, Abdulahi M. Utilization of Family Planning Services and Influencing Factors Among Women of Child Bearing Age in Assosa District, Benishangul Gumuz Regional State, West Ethiopia. Science Journal of Clinical Medicine. 2015;4 (3):52-59.

15. Fikirte T,Walelegn W, Fekadu M,Manay K. Knowledge, Perception and Utilization of Postnatal Care of Mothers in Gondar Zuria

District, Ethiopia: A Cross-Sectional Study. Matern Child Health J. 2014;18:2341-51.

16. Berhe H, Tilahun W, Aregay A, Bruh G, Gebremedhin H. Utilization and Associated Factors of Postnatal Care In Adwa Town, Tigray,ethiopia- A Cross Sectional Study. Advance research in Pharmacuiticals and Biologicals. 2013;3(1):353-59.

17. Regassa N. Antenatal and postnatal care service utilization in southern Ethiopia:a population-based study. African Health Sciences.2011:11(3):390-97.

18. Mulatu A, Samrawit S, Molla G, Habte B. Postnatal Care Service Utilization and Associated Factors among Women in Dembecha District, Northwest Ethiopia. Science Journal of Public Health. 2015;3(5): 686-92.

19. Yinager G, Desta A. Factors Affecting Utilization of Postnatal Care Service in Amhara Region, Jabitena District, Ethiopia. Science Journal of Public Health. 2014; 2(3):169-76.

20. JemalA, Damen H. Determinants of equity in utilization of maternal health services in Butajira, Southern Ethiopia.Ethiopian Journal Health Development.2012; 26: 266-270.

21. ZelekeD, Nega A, Gudina E. Maternal health care use among married women in Hossaina, Ethiopia. BMC Health Services Research, 2015;15:365.

22. Asfawosen A, Mussie A, Huruy A, Wondeweson T.Factors associated with maternal health care services in Enderta District, Tigray, Northern Ethiopia.American Journal of Nursing Science. 2014;3(6):117-125.

DOI: http://dx.doi.org/10.4314/ejhs.v28i3.4 